\title{
Student-centered and ability training- oriented curriculum reform in teaching Microcontroller Principles and Interface Techniques
}

Xiaoping Wang, Peijun Cai, Yuling Liu, Liqiang Wang, Yiyong Liang

Xiaoping Wang, Peijun Cai, Yuling Liu, Liqiang Wang, Yiyong Liang, "Studentcentered and ability training-oriented curriculum reform in teaching Microcontroller Principles and Interface Techniques," Proc. SPIE 10452, 14th Conference on Education and Training in Optics and Photonics: ETOP 2017, 104520W (16 August 2017); doi: 10.1117/12.2267205

SPIE Event: 14th Conference on Education and Training in Optics and Photonics, ETOP 2017, 2017, Hangzhou, China 


\title{
Student-centered and ability-training-oriented curriculum reform in teaching Microcontroller Principles and Interface Techniques
}

\author{
Xiaoping Wang ${ }^{*}$, Peijun Cai, Yuling Liu, Liqiang Wang, Yiyong Liang \\ College of Optical Science and Engineering, Zhejiang University, Hangzhou 310027, China
}

\begin{abstract}
Courses are an important way of cultivating talents in college education. Advanced training schemes and the course system are implemented through course teaching. Advanced teaching notions and methods also rely on course teaching. Therefore, the quality of course teaching is the fundamental guarantor for grooming talent. The teachers of the course "Microcontroller Principles and Interface Techniques" in the Optical Science and Engineering College of Zhejiang University insist on course teaching becoming student centered and ability-training-oriented. They pay attention to students'all-round development in terms of learning ability, practical ability, innovation ability, and exploring spirit. They actively carried out course reforms in four aspects, namely teaching, learning, evaluation, and experimentation. This paper mainly introduced these reforms. First, the teaching method was reformed by introducing case analysis and the notion of a flipped classroom to shift the course focus from the teacher to the students. Second, the learning method was reformed through the use of techniques such as peer learning and project design to promote students' sense of enquiry and learning initiative. Third, the evaluation method was reformed through the use of process assessment and diversity evaluation to encourage students to develop logical thinking and a down-to-earth manner. Fourth, the experimentation method was reformed by introducing hierarchical content, process management, and diversification of examination to change students'learning attitude from "dependence, passivity, and imitation" to "independence, active involvement, and creation."In general, the teaching method reform promoted reforms in learning, evaluation, and experimentation methods and further improved the style of study. These reforms improved teachers' teaching abilities and enabled course teaching to transform from being teacher centered to student centered. Years of exploration and practice results have shown that such reforms not only effectively inspire students to learn, explore, and practice actively,
\end{abstract}

\footnotetext{
*Xiaoping Wang, E-mail address: xpwang@zju.edu.cn.
}

14th Conference on Education and Training in Optics and Photonics: ETOP 2017, edited by Xu Liu,

Xi-Cheng Zhang, Proc. of SPIE Vol. 10452, 104520W · C 2017 ICO, IEEE, OSA, SPIE

CCC code: $0277-786 \mathrm{X} / 17 / \$ 18 \cdot$ doi: $10.1117 / 12.2267205$ 
but also cultivate their creative spirit and courage to face challenges, providing a good platform for theirself-learning and personal growth. The course reforms discussed here have been highly recommended for their reference value.

Key words: student-centered; teaching method; learning method; evaluation method; experimentation method

\section{INTRODUCTION}

With strong support from the nation, Zhejiang University cherishes its ambition to be a world-class university. It respects people-oriented, integrated training, pragmatic innovation, and the pursuit of excellence of educational philosophy, and advocates the educational aim to develop top creative talent and future leaders with good knowledge, ability, quality, pragmatic innovation spirit, and international vision. Therefore, it actively promotes teaching innovation and course construction. In the 2015 Zhejiang University Education Teaching Discussion Conference, President $\mathrm{Wu}$ pointed out that the talent training effect depended on scientific teaching methods. He advocated and encouraged teachers to reform traditional teaching patterns and further carry out participatory, heuristic, discussing and research teaching ${ }^{[1]}$.

As a consequence,the main research topics of teaching reform include the following sections: carry out research teaching from spreading knowledge to cultivating ability; stimulate students' learning initiative, enthusiasm, and exploration spirit; adopt individuation teaching so as to create conditions for outstanding students to develop themselves; change the traditional experiment mode that emphasizes results and overlooks the process, and improve students' comprehensive practical ability.

\section{CURRICULUM TRAINING TARGET AND TEACHING IDEA}

The course "Microcontroller Principles and Interface Techniques" has a strong engineering foundation and application value. It is one of the key college courses offering a specialty in electronics information, instruments, and computers, and it plays an influential role in university engineering students' education. The teachers of the course in the Optical Science and Engineering College of Zhejiang University put forward training targets in consideration of the characteristic of the course.After course theory study, students can understand and master the knowledge systematically, including the system structure, the functional model, and interface techniques. After practical training, students can master microcontroller programming and debugging methods and further learn microcontroller application system design, 
development, and debugging capabilities.In general, the objective is to cultivate students'learning and development abilities and analysis and problem-solving abilities by combining theory with practice and creativity, which are indispensable abilities for university science students ${ }^{[2]}$.

To achieve these objectives, the teachers insisted on teaching student-centered and ability-training-oriented ideas. They combined knowledge teaching and learning, innovation, and practical ability cultivation. Furthermore, advanced reforms, including new teaching methods, learning methods, evaluation methods, and experimentation methods were carried out by the teachers ${ }^{[3]}$.

\section{CURRICULUM TEACHING REFORM}

\subsection{Reformed teaching method and launched research teaching}

Students learn knowledge but also study attitudes toward scientific investigation and scientific thinking methods from teachers' teaching process and methods ${ }^{[4]}$. Therefore, optimizing the teaching procedure and reforming the teaching method are the focal points of course reform. By applying case teaching, flipped classroom, and chapter summary, the teaching method was changed into the instructive type. At the same time, the teachers transformed their role from knowledge teachers to organizers, and directors, aids, and promoters who could help students study on their own initiative. They aroused students' interest and expanded their study horizons. Finally, the focus in class shifted from the "teacher centeredness" to "student centeredness."

\section{(1) Implemented case teaching and conducted discussions}

Case teaching is a teaching method that encourages students to make analysis and conduct discussions through description of a concrete educational situation. The teachers supplemented their teaching with case studies to enhance students' understanding and help them grasp important and difficult points, avoiding compulsory education or the comprehensive teaching style brought about by the situation of poor learning outcomes. For example, through an actual example of a crossroad traffic light, students could quickly understand the different working ways of timers and the two kinds of response mode (inquiry and interruption). Through the use of a simple electronic organ, students could understand and master the matrix keyboard's working principle and interface advantage. This practice showed that case teaching could strengthen the correlation between curriculum knowledge and the real world and help to broaden students' professional views. 


\section{(2) Introduced flipped teaching and promoted learner autonomy}

Flipped classroom is a kind of new class mode. The teachers require students to autonomously learn teaching resources online and refer information. Students prepare lecture notes covering major topics and then discuss and analyze the topics with others in class. Another method is chapter summary. This requires students to summarize a chapter's content according to their own learning, understanding, and digestion. They share and communicate with others in class. In flipped teaching, the roles were switched between teachers and students. The classroom became a good platform that the teacher and students could actively communicate and interact in. The students deeply understood the relevant theories of microcontroller principles and application and interface techniques through class discussions. Flipped teaching strengthened students' learning initiative, promoted the integration of course knowledge, and helped set up a complete knowledge system.

\subsection{Reformed learning method and promoted research study}

Both autonomous learning and free inquiry are the precondition for creativity formation, which is in turn affected by creativity development. They rely on each other and become essential learning attitudes that innovation-type talents $\operatorname{possess}^{[5]}$. A series of measures were implemented to strengthen students' autonomous learning, free inquiry, and creativity. By constructing a learning community, students accomplished course exploratory tasks via group work. Through "excellent student waiver," which refers to project learning and study, students had the opportunity to give full play to their independent thinking and creativity. In general, the goal of learning method reform was to change students' learning concept from "passive, exam-oriented learning" to "autonomous inquiry learning."A new teaching system was formed that combined classroom teaching and activity after class.

\section{(1)Formed a learning community and explored "peer learning"}

Students in the course were divided into 10-12 groups, each composed of 3-4 persons. They conducted mutual learning after class, such as preparing the lecture notes for the "flipped classroom" and summarizing chapter content through discussions. This kind of peer cooperation learning has many advantages in contrast with traditional individual learning. The students reflected that they could learn from each other, supervise each other, and complement each other. Through discussion, they inspired talent and had epiphanies about ambiguous concepts and difficult points. Under the guidance of the group leader, they shared different opinions, performed their respective duties to accomplish exploratory tasks, and further enhanced their personal responsibility and collective cohesion. 


\section{(2) Pushed "excellent student waiver" to implement individuation teaching}

"Excellent student waiver" is a concept of project learning and study. It is centered on students and aims to cultivate their abilities. Students who had any energy left applied to be excused from the final written examination and submitted an answer using a combination of course and relevant knowledge, namely designing a microcontroller application system. They went through the whole process of scientific research, including project application, independent research, schema design, debugging, summarizing, and defending. "Excellent student waiver" gave students an environment more suitable for creative and independent learning. It also inspired their passion to learn and developed their talents and innovation potential. This is an effective method to realize different education and individuation teaching and can promote the interaction of teaching and scientific research, learning, and research.

In the past nine years, nearly 200 students have designed more than 90 creative microcontroller application systems that have been integrated with optics, precision apparatus, electron and computer technology, etc. Students' creative desire, creativity, and work quality were far beyond the teacher's expectations. For example, the system "laser engraving machine based on 8051 microcontroller" had the characteristics of quasi device. It used a rectangular coordinate frame and high-power laser, ablated in ordinary cardboard point by point and then carved out a clear pattern and character.Another project was a "laser drawing system based on a microcontroller,"which made bold attempts to introduce a 2D laser scanning system and could described a stable monochrome pattern with a cheap cost. In addition, the "acoustic aurora LED system" showed a magical pattern shape and gorgeous color changes on an LED circular array; the "dynamic light screen system,"which controlled equipment and linkage show effects through gestures, could be regarded as the prototype of virtual reality in the future; "intelligent bicycle wheels spinning LED display system" exemplified young people's movement, sunshine, and passion through the cool dynamic display of bicycle wheels. The reforms of "excellent student waiver" have received widespread praise. Many students thought that the project design experience enhanced their endurance and spirit of challenge and became more confident about conquering future difficulties.

\section{(3) Arranged exploratory task to guide students' diverging thoughts}

Exploratory tasks such as organizing examination papers were assigned to students to guide their divergent thinking and strengthen their exploring consciousness. Teachers requested that such papers should contain different types of subjective/objective questions and that students should add annotations about each question's knowledge points. To 
complete the task, the students had to comprehensively organize all the course knowledge. They needed to understand the emphasis and difficulty and grasp the course overall context. Students also had access to a large number of studies for in-depth analysis and thinking so that they could elaborately design the paper to judge the learning effect. Papers submitted by students contained different text types and difficulties, including true or false, multiple choice, blank filling, short answers, and coding and comprehensive design. The content of the papers covered comprehensive and clear knowledge and well embodied the divergent thinking of students.

\subsection{Reformed evaluation method and promoted pragmatic study style}

The teaching method and learning method reforms promoted the reform of evaluation method. Process assessment and diversity evaluation were applied to end the phenomenon of cramming for exams, and utilitarian study turned into pragmatic study. Changes were made to evaluation method from results assessment to a combination of assessment of process and results. These changes helped to form a "seeking truth from facts" study atmosphere.

\section{(1) Adopted diversified evaluation to assess comprehensive ability}

Students' score became more objective and impartial by perfecting the evaluation system. The course grade of the students participating in "excellent student waiver" was divided into four parts, namely, peacetime performance, process test, project design, and awarding points. Other students' grades were divided into five parts: peacetime performance, process test, experimentation, final exam, and awarding points. Each part had multiple elements, while different elements evaluated students' knowledge and ability from different aspects. Various methods of encouragement were used to promote students' enthusiasm for learning. All the students conducted questionnaire investigation. The students participated in chapter summary, and organizing examination papers accounted for $51 \%$ and $45 \%$ respectively.

\section{(2) Adopted process assessment to promote comprehensive development}

Each element of diversified evaluation was supported by process assessment. Peacetime performance included ten homework assignments, self-study, and cooperation study after the classroom. Process test included at least six instances of online testing and four instances of class testing. Experimental grade covered the whole process of experiment preview, simulation, operation, testing, results, and reporting.

\subsection{Reformed experimentation method and promoted practical application of knowledge}

Experimental teaching is an important method to enhance students' practical abilities and innovation ideas. Science experiment teaching needs to have multiple teaching designs, appropriate teaching processes, and a fair and 
comprehensive evaluation system ${ }^{[6]}$. To significantly enhance the effect of the experiment, the teachers set hierarchical, progressive experiment content and carried out an opening autonomous experiment, heuristic experiment guidance, process management, and diversified experiment examination. This new experimentation teaching mode led to three transformations in students: from dependence on counseling to independent design, from passive acceptance to initiative discovery, from pure imitation to personal creation.

\section{(1) Set up a hierarchical experiment to exert students' potential}

Hierarchical experimentation,including basic and comprehensive inquiry contents, not only helps students consolidate and apply what they have learned but also helps them exercise their progressive practice though theory verification and comprehensive application. Inquiry experiment contents were optional. After completing regular experiments, students were free to select the inquiry contents. This mode offered students a chance to show their abilities and facilitated a change from passive participation to positive selection.

Considering the needs of hierarchical experimentation, as well as the rapid development of microcontroller techniques, the teachers have researched and offered different types of experiment systems to keep pace with the times,such as a traditional system with external emulator and a new-type system with ISP technology and high speed USB interface. The experiment systems were convenient for handing out to each student so that they could carry out the experiment and cultivate practical ability wherever and whenever they wanted.Open experiments in time, space, and content were truly performed.

\section{(2) Implemented reform of various aspects to improve experimental effect}

Heuristic experiment guidance was adopted. The teachers only gave basic design ideas and key hints instead of detailed steps. For example, in the serial communication experiment, the teachers prompted students first to make communication protocols and then test them through serial debug terminal, open communication data buffer, etc. Without experimental steps, hardware connection diagram and sample programs, students had more freedom with experimental design and exploration. Process management was pursued. Students pre-studied the experiment, passed the preview test, and then booked experimental time. During the experiment, they were questioned about the hardware connection mode, the structure of the main program, design thought, and problems and solutions. Students were even required to improvisatorially improve the experiments. Only students who completed the experiment independently with deep thinking could respond to the requirements quickly and correctly. Quizzes about the experimental contents were 
added to test related knowledge and skill points. Finally, a report that complied with the specifications was needed.Diversified experiment examination was also carried out. Each link in the process of the experiment was evaluated in detail, such as Proteus simulation, experimental process and completion, and experimental test and report.

\section{CONCLUSION}

Teaching is at the core of higher education and the main way to cultivate talent. The teaching activities of traditional education were centered on class, teachers, and textbooks. Teaching methods have been unable to meet the goal of cultivating creative talents. In fact, teaching is the external cause, while learning is internal. Teaching takes on its role through learning ${ }^{[7]}$. Therefore, teaching should be centered on students instead of teachers. The stress of teaching should be shifted from spreading knowledge to cultivating ability. The teaching method of preaching and imparting knowledge in the general sense should be changed to inspiration and guiding students, stimulating students to learn, and guiding students to think and solve problems independently. On the basis of this thinking,a comprehensive and systematic reform of the "Microcontroller Principles and Interface Techniques" course was carried out. The reform emphasized research teaching, guidance, and encouragement of teachers(teaching method); inquiry and independent learning of students(learning method); especially, differential treatment and realistic spirit(evaluation method);and study and application integration(experimentation method). The omnidirectional course reform combined teaching, learning, evaluation, and experimentation inspired students' subjective initiative of learning, exploration, practice, and innovation; and played an active role in enhancing the students' practical ability, creative spirit, and scientific literacy.

\section{REFERENCES}

[1] Wu,C.H., "Strengthen innovating training mechanism and build talent cultivation system with rearing people as the fundamental task and all-round development as the goal," Education teaching discussion mobilization meeting of Zhejiang University, (2015).

[2]Guo,Z.N., Luo,J. E., and Chen, L., "Reflections on the Educational Reform of Higher Engineering Education," THEORY AND PRACTICE OF HIGHER EDUCATION IN BUILDING MATERIAL SCIENCE. 20(5),7-9 (2001).

[3] Wang, X. P., Liang, Y. Y., Wang, L. Q., Liu, Y. L.,Cai, P. J. and Qi, H. L., "Microcontroller Principles and Interface Techniques Curriculum Reform and Practice Based on Students," First award of Zhejiang University teaching achievement prize,(2016).

[4] Karl Jaspers. [Was ist Erziehung?], San Lian Press, Beijing, 139 (1991).

[5]Zhan, T., "Thoughts on Innovative Talent Cultivation in Research-oriented Universities," Journal of Higher Education. 32(1), 7-13 (2011). 
[6] Zhang, Z. M. and Li, T. T., "Application of Performance Assessment in Teaching of Engineering Experiment," GuangZhou Chemical Industry and Technology. 40(9),227-229 (2012).

[7] Lu, G. D., "The Current Situation of University Education and Reform on Teaching Methods in China," China Higher Education. 23,42-44(2013).

Proc. of SPIE Vol. 10452 104520W-9

Downloaded From: https://www.spiedigitallibrary.org/conference-proceedings-of-spie on 26 Apr 2023 Terms of Use: https://www.spiedigitallibrary.org/terms-of-use 